\title{
FUNDAMENTAÇÃO DE VALORES NO DIREITO: A NECESSIDADE DE UMA MUDANÇA DE PERSPECTIVA METODOLÓGICA PARA A EFETIVIDADE DOS DIREITOS FUNDAMENTAIS NO DISCURSO JURÍDICO
}

\author{
Daniel Fioreze Saggin ${ }^{1}$ \\ Jair Pereira Coitinho
}

\begin{abstract}
Resumo: em um primeiro momento, o artigo abordará o discurso jurídico enquanto ciência de Estado, a partir da modernidade, pois esse tempo tem como marca fundamental o Estado como ente centralizador e produtor de normas. Em um segundo momento será analisado o corte retórico no âmago dos postulados científicos jurídicos, notadamente pela teoria normativista do Direito desenvolvida por Hans Kelsen, em que o discurso jurídico estaria pretensamente apartado de questões sociais e políticas. Posteriormente, parte-se da hipótese do Direito como instituição cultural e a problemática do pouso do sentido normativo no tecido social. Por fim, será analisada a possibilidade de uma postura prescritiva do Direito, onde se evidenciará a necessidade de fundamentar e dar consistência a valores no interior do próprio discurso jurídico, já que não existe um lugar privilegiado para fundamentar valores a não ser através de uma teoria da argumentação, considerando o sujeito das normas no contexto em que emerge, nas condições sociais e políticas que lhe são inerentes. Assim, o presente trabalho tem como fio condutor esta temática, que exige do discurso jurídico, na contemporaneidade, uma mudança de perspectiva metodológica como condição para a efetivação e compreensão dos Direitos fundamentais.
\end{abstract}

Palavras chave: Discurso Jurídico. Racionalidade Instrumental. Epistemologia. Direitos Fundamentais. Hermenêutica.

\section{INTRODUÇÃO}

Pôr em debate a questão da racionalidade, nas ciências do espírito, implica, necessariamente, na busca da consistência interna de seus discursos e, ao mesmo tempo, reconhecer que inexiste, para tal, um meta-domínio ou um lugar privilegiado para sua realização. Já não podemos "explicar” o mundo de um lugar “desde fora”, através de metafísicas. Eis nosso fardo e nosso privilégio: fardo, pois já não podemos justificar nossas visões de mundo numa dimensão sagrada ou transcendente e, para tanto, devemos nos resignar com a “relatividade de toda opinião” (WEBER, 1989, p. 30). Porém, ainda que profano, nosso privilégio é de termos assumido - assim nos parece - o “domínio” da

\footnotetext{
${ }^{1}$ Mestrando pela Universidade Federal de Santa Maria/RS. Especialista em Direito Processual Civil no Complexo Educacional Damásio de Jesus. (UFSM).

${ }^{2}$ Doutorando em Direito Constitucional pela UNIFOR - Universidade de Fortaleza (CE). Mestre em Direito pela PUC-RS - Pontifícia Universidade Católica do Rio Grande do Sul (2007).
} 
vida. Sabemo-nos sujeitos históricos e culturais que, ao produzirmos linguagem, produzimos mundos. Devemos reconhecer, em nossa finitude, a provisoriedade de nossas proposições que, para a produção dos saberes, implica no reconhecimento de uma dinamização e temporalização daquilo que produzimos enquanto saber propriamente dito, tanto a nível científico (regional), quanto a nível epistemológico (fundamental). Max Weber (idem, ibidem) denuncia com precisão de desabafo o ambiente que se inaugura na modernidade: “já não podemos nos sentir plenos, talvez, e apenas isso, cansados diante de nossa finitude”.

No que interessa à epistemologia, “um discurso sobre o qual o discurso primeiro da ciência deveria ser refletido” (JAPIASSU, 1977, p. 24), isso terá uma série de consequências, pois não podemos mais pretender produzir um discurso universal, necessário e verdadeiro, como sustentava, por exemplo, o idealismo absoluto de Hegel: enquanto a concepção de ciência pertenceu à filosofia, até a “morte” da grande filosofia, as exigências para a produção do saber deveriam cumprir com tal expediente. Mas aí a produção do saber ainda se fundava na dimensão do sagrado (no caso de Hegel, no espírito absoluto). Porém, se o "fardo" nos tem algum peso hoje, é de saber que tudo o que produzimos é tão provisório quanto finito, e até mesmo na ciência está inscrita nossa finitude, já que devemos reconhecer nela a pluralidade - cultural - de argumentos possíveis. É varia a forma de pensar, pois igualmente polissêmicas as culturas. E não podemos nos sobrepor a um ou outro argumento senão através do diálogo e da coerência. Do contrário, que se admita então a dominação de culturas através de violência massiva. Talvez aí uma contradição para os ufanados Direitos Humanos, que, em sua hegemonia, levanta tímido semblante de absolutização da sua legalidade, em claro detrimento da sua legitimidade, passível de ser realizada somente através de uma teoria da argumentação. Esta, por sua vez, é condição de possibilidade para a produção de uma racionalidade em qualquer discurso no campo das ciências do espírito, pois valores e sentidos não nos são possível justificar cientificamente, apenas pressupô-los na realização cientifica. Logo, a questão que molesta qualquer empreendimento epistemológico é: “como, enfim, construir uma boa racionalidade ao nível de uma epistemologia que tem como intenção fundamental buscar a justificação de enunciados (o que significa buscar a consistência interna de um discurso [...])?” (STEIN, 1987, p. 51). Como produzir um saber racional, mesmo ciente de sua provisoriedade, "relatividade” cultural e pluralidade?

$\mathrm{Na}$ epistemologia jurídica, a discussão acerca da racionalidade estabelece, imediatamente, um embate entre um tipo de racionalidade instrumental (de enunciados 
descritivos): insuficiente em dar conta das articulações do mundo jurídico, posto que polissêmico, contextual, político e não unidimensional; e entre um tipo de racionalidade comunicativa, e a problemática de justificar valores, sentidos e preceitos éticos, justamente por não termos lugar privilegiado para a realização do discurso. No fim, parece-nos insuperável qualquer discussão sobre o método. Bem, este último tipo de racionalidade, a racionalidade comunicativa, somente ocorre através de estruturas histórico-compreensivas (hermenêuticas) e pelos atos de fala, já que impossível, para o humano, agarrar-se a um microscópio e através dele visualizar o que chamamos "vida”, "liberdade” ou “igualdade” ou qualquer conceito jurídico indeterminado. No Direito isso será a realização da democracia: condição de um povo, e não um estado político. No entanto, isso evoca dois problemas preliminares: o primeiro é de que a postura instrumental da racionalidade é inadequada para a epistemologia jurídica; a segunda é de que a racionalidade comunicativa tem como elemento precípuo, para sua produção, a legitimidade, ou seja, a discussão de valores e preceitos éticos através de um agir comunicativo. Na linguagem habermasiana, a isso se denomina Estado Democrático de Direito, abrindo um horizonte hermenêutico, ou seja, de compreensão histórica. Na verdade, o discurso jurídico “caminha” sobre um chão (da compreensão e do mundo da vida), que é o chão da legitimidade: sem ele, o Direito não se sustenta.

\section{RACIONALIDADE E EPISTEMOLOGIA DO DIREITO: O OCASO DOS DISCURSOS JURÍDICOS ORDINÁRIOS}

A contribuição da teoria de Kelsen para se pensar uma ciência do direito foi determinante. Pode-se dizer ainda que, antes de Kelsen, não se tinha condições de se pensar em uma ciência do direito nos patamares que se entendia a ciência na modernidade. A contribuição kelseniana indica "as bases necessárias para o conhecimento da estrutura do Direito positivo" na modernidade (WARAT, 1996, p. 47). A emergência de se pensar o direito de forma cientificamente organizado é uma exigência da própria modernidade, já que a racionalidade dominante na modernidade é a racionalidade científica em seu legado positivista. Qualquer discurso que não fosse orientado sob tais patamares estaria fadado ao desconhecimento, inclusive pelo poder de “constrangimento” epistemológico que a racionalidade científica exercia sob a validade do discurso e do saber produzido 
naquele momento. Neste sentido, a racionalidade do discurso jurídico científico dependeria de seu grau de coerência com os postulados modernos e positivistas.

A racionalidade do discurso jurídico dependeria de sua capacidade de ser inferido enquanto discurso científico, dentro de uma estrutura positivista. Desta forma, para se pensar uma ciência jurídica, isso exigiria um processo de purificação do direito (enquanto ciência) que se resolveria na própria delimitação do objeto desta ciência ${ }^{1}$. Nos dizeres de Albano Pêpe (2002, p. 57):

Neste processo de cientificização do Direito, encontramos os postulados de Hans Kelsen, que ao desenvolver sua 'Teoria Pura do Direito', propõe-se metodologicamente a delimitar as fronteiras da ciência do Direito em relação às questões tanto da Ética, como da Moral e da Política.

E Conforme Kelsen (1998, p. 2),

[...] como teoria, quer única e exclusivamente conhecer o seu próprio objeto. Procura responder a esta questão: o que é e como é o Direito? Mas já não lhe importa a questão de saber como deve ser o Direito, ou como deve ele ser feito. É ciência jurídica e não política do Direito.

Até então, o Direito se confundia, por assim dizer, com outras instituições sociais. “O direito enquanto compreensão normativa dos sistemas de organização social prémodernos (mundo grego clássico, mundo medieval) fazia parte de um 'amálgama normativo' vinculante, no qual ele não era distinto de outros sistemas normativos tais como Moral e a religião” (PÊPE, 2002, p. 58). E aqui reside a importante tarefa de Kelsen ao pensar o direito enquanto ciência, posto que - é de se lembrar -, na modernidade, em decorrência de sua típica racionalidade instrumental, as áreas de saber que detinham voz capazes de serem ouvidas eram, notadamente, os conhecimentos dotados de cientificidade, discursos que operavam como a ciência em níveis lógicos, epistemológicos e metodológicos. Nos dizeres de Luis Alberto Warat (1995, p. 47):

Kelsen acentuou a inexistência de uma metodologia adequada para construir uma teoria científica baseada na objetiva e sistemática descrição das normas positivas, bem como a necessidade de elaborá-la a partir de conceitos rigorosos que extirpassem do conhecimento jurídico qualquer tipo de interferência ideológica. Sugeria, também, a construção de uma epistemologia da qual se deveria retirar a crítica do saber jurídico tradicional, um saber inadequadamente assumido como científico.

\footnotetext{
1 “[...] o ideal de pureza implica em separar o conhecimento jurídico, do direito natural, da metafísica, da
} moral, da ideologia e da política”. (ROCHA, 2008, p. 1037). 
Em atenção a isso, Kelsen, na produção de sua teoria pura, afastou tudo que desinteressava a concepção estrita de Direito enquanto ciência². Assim, “a preocupação de Kelsen nunca esteve diretamente relacionada ao Direito, e sim à ciência jurídica” (WARAT; PÊPE, 1996, p. 48). O que é a ciência do Direito é a pergunta que motiva os trabalhos de Hans Kelsen no Direito. "Sua pretensão era construir uma ciência jurídica em sentido estrito” (idem, ibidem, p. 49). Significa dizer que uma ciência jurídica deveria estar restrita ao olhar de seu objeto, ou seja, "um ponto de vista necessariamente normativo. Assim, postulou uma Ciência do Direito pensada como uma ciência normativa do Direito” (idem, ibidem, p. 49). É de se lembrar que a norma é o objeto da ciência jurídica, entretanto

Ele não negava o valor do conhecimento produzido por outras áreas do saber no que diz respeito ao Direito, como a sociologia, a ética ou as ciências políticas, mas sua meta era caracterizar o objeto particular da ciência jurídica, ou o Direito como objeto de um saber autônomo, regido por leis que lhe são próprias. (idem, ibidem, p. 49).

Não se está dizendo que somente a ciência jurídica estava pretendendo alcançar patamares da racionalidade moderna e que as demais ciências não eram racionais. O Direito foi um dos últimos saberes a cientificizar seu discurso e, evidentemente que outras áreas do saber já gozavam de uma racionalidade em suas proposições. Ocorre que, ainda assim, estas áreas não deveriam importar ao Direito no seu esforço de cientifização, posto que a ciência jurídica deveria ficar adstrita a seu próprio objeto, não se socorrendo de outros saberes para pensar a si própria. Deveria ser uma ciência autônoma e que desse conta de seus postulados em sua estrutura dogmática e epistemológica. Bem, diante de uma sociedade em que o discurso tido como válido era o discurso científico, onde qualquer saber que não estivesse eivado de um caráter de cientificidade era desconsiderado, Kelsen acabou, então, por dotar o direito de cientificidade para que assim pudesse estabelecer um discurso entendido como racional. Porém, a racionalidade científica do discurso jurídico deveria, imediatamente, observar dois fundamentos necessários: um fundamento epistemológico ${ }^{3}$ e outro dogmático. "Sua meta era

\footnotetext{
${ }^{2}$ Neste sentido: "Kelsen teorizou, de maneira extremamente brilhante, a questão da racionalidade. Kelsen, já no início do século XX, tentou construir uma Ciência do Direito. Uma ciência como uma teoria apta a reduzir a complexidade do mundo por meio de um sistema dotado de uma metodologia lógico-dedutiva”. (ROCHA, 2009, p. 49).

3 “[...] a epistemologia teria a missão de construir um sistema unitário e rigoroso de conhecimento sobre as normas e as teorias com que se pretende descreve-las. Seria, basicamente, uma instância de controle da
} 
caracterizar o objeto particular da ciência jurídica, ou o Direito, como objeto de um saber autônomo, regido por leis que lhe são próprias” (idem, ibidem, p. 49). Assim sendo, o rigor científico exigido do discurso jurídico implicaria "tanto a elaboração de normas metodológicas adequadas à produção do saber dogmático do direito, como também o desenvolvimento das categorias gerais desse modelo de conhecimento para se pensar uma epistemologia dogmática “geral” (WARAT; PÊPE, 1996, p. 47).

Para Kelsen, a autonomia da ciência jurídica requer sua libertação de todos os elementos que lhe são estranhos. A Ciência do Direito deve apenas pretender construir um conhecimento que tente responder às questões 'o que é' e 'como é' o Direito, sem procurar explicitá-lo, transformá-lo, justifica-lo, nem desqualifica-lo a partir de pontos de vista que lhe são alheios. Essa é a exigência metodológica fundamental que define o sentido da idéia de pureza. (idem, ibidem, p. 49).

Neste sentido, a dogmática jurídica, enquanto método, "seu objetivo primordial foi estabelecer categorias e bases metodológicas que permitissem compreender sistematicamente toda norma jurídica científica”. A metodologia deveria ter objetivos claros quanto a seu objeto, separando desse objeto tudo o que não lhe interessava enquanto ciência, tais como questões de política do direito e outras valorações sociais de disciplinas que não interessavam a norma jurídica enquanto elemento fundante e objetivo da ciência jurídica: “é a atividade que tem a pretensão de estudar, sem emitir juízos de valor, o direito positivo vigente. É a pretensão de elaborar uma teoria sistemática do direito positivo. A atitude científica do Direito estaria na aceitação inquestionada do direito positivo vigente” (idem, ibidem, p. 48). A abordagem realizada por Luis Alberto Warat e Albano Pêpe (ibidem, p. 48) trazem maior lucidez ao tema:

\begin{abstract}
O desenvolvimento de sua teoria teve sempre como finalidade a elucidação do pensamento dogmático do Direito, ou seja, daquele pensamento cujas proposições são tomadas como princípios inegáveis no sistema desenvolvido, investigação essa realizada no interior da ciência dogmática, conforme o modo de proceder kantiano, ou seja, tomando a ciência positiva como ponto inicial de todo empreendimento epistemológico. O interesse da teoria pura é, portanto, tornar evidente as condições de positividade da ciência jurídico-positiva.
\end{abstract}

Vale lembrar que a grande instituição da modernidade é o Estado, e isso será determinante para se pensar a ciência jurídica no aspecto dogmático de sua racionalidade, especificamente em sua racionalidade dinâmica. A organização dogmática da ciência produção de um conhecimento rigoroso". (WARAT; PÊPE, 1995, p. 48). 
jurídica tinha, então, como condição de possibilidade de seu discurso, a existência de um “ente” central produtor de normas. "Direito dogmático é direito posto pelo Estado moderno" ${ }^{4}$. Notadamente, esta racionalidade dinâmica está na "pirâmide de Kelsen”, no que trata sua estrutura de validade hierárquica das normas. Como o Estado é a figura central da modernidade, isso foi facilmente solucionado, num ponto de vista de organização da dogmática que estava se propondo. O Estado é o centro produtor de normas: "sistema para trato com certo tipo de relações previamente determinadas, que decida em última instância sobre questões relacionadas com o próprio sistema, monopolizando a definição do direito” (ADEODATO, 1999/2000, p. 168).

Neste postulado de um direito dogmaticamente organizado e centralizado na figura do Estado (ente produtor de normas positivas), não importava a ele os conteúdos na produção de uma ciência jurídica, quer dizer, a pureza, para Kelsen, está na forma de olhar e não na coisa olhada. Portanto, Kelsen, na estruturação de uma teoria pura do direito, estava muito mais voltado às formas (forma de olhar) do que ao conteúdo do Direito, que ficaria a cargo da política ou do jurista na sua experiência" . "Por tudo isso, Kelsen imagina que o objeto de um saber jurídico não pode ser mais do que o conjunto das normas positivas de um Estado, apreendidas do ponto de vista de suas formas”6 (WARAT; PÊPE, 1996, p. 51). A ciência jurídica, no que trata seu aspecto dogmático, imuniza do Direito outros conhecimentos que não cumpriam com objetivos de purificação desse Direito. “Uma sociedade só estará potencialmente apta a dogmatizar seu direito se

\footnotetext{
${ }^{4}$ Ainda neste sentido: “Assim, como primeiro constrangimento, coloca-se a obrigatoriedade de estabelecer textos normativos, fixar previamente os pontos de partida para as regras do jogo. Daí a expressão dogmática jurídica, pois são precisamente esses textos os dogmas que procuram fixar os limites que, apesar de elásticos, não deve ser explicitamente negados. Nos sistemas jurídicos democráticos, informados pela separação dos poderes, tal função fica mais a cargo do poder legislativo e, cada vez mais no mundo moderno, mais ainda nos países subdesenvolvidos, a cargo do pode executivo.[...]". (ADEODATO, 1999/2000, p. 155-173) (grifo do autor).

5 "Para ele, o social (e o direito) são devido as suas heteróclitas manifestações constituídas por aspectos políticos, éticos, religiosos, psicológicos e históricos. E a esse respeito não cabe ao cientista do direito nada comentar. A função do cientista é a construção de um objeto analítico próprio e distinto destas influências. A partir destas constatações é que Kelsen vai procurar, assim como Kant, depurar essa diversidade e elaborar uma 'ciência do direito'. Ou seja, na teoria pura uma coisa é o direito, outra distinta é a ciências do direito. O direito é linguagem objeto e a ciência do direito a meta-linguagem: dois planos linguísticos diferentes". (ROCHA, p. 1038).

${ }^{6}$ Complementando a questão: "Kelsen, ao afirmar que a ciência jurídica não tem outro objeto senão o Direito positivo, nega também o direito natural. Ao assumir esta postura, ele retoma de alguma forma a tradição positivista do século XIX, rejeitando a possibilidade de aceitar um direito transcendente, anterior e superior ao Direito positivo. Ele diria que o direito natural é uma forma irracional, puramente emocional, de construir um modelo de referências valorativas, erguidas a partir de um árbitro retórico dos conteúdos do Direito positivo. Dessa forma, o direito natural aparece como ideologia, permitindo também encobrir o exercício de um certo poder jurídico. Assim, em nome do direito natural (invocando o nome de Deus, a Natureza ou a Razão), certos homens exercer o poder jurídico e tomam decisões pelas quais não se responsabilizam" (idem, ibidem, p. 51).
} 
houver uma relativa emancipação do sistema jurídico em relação às demais ordens normativas e aos demais subsistemas sociais” (ADEODATO, 1999/2000, p. 168).

É de se dizer que este entendimento dogmático do Direito é correspondente ao próprio imaginário moderno, daí a necessidade de se produzir um discurso jurídico cuja racionalidade se adequasse ao expediente da modernidade: o Direito enquanto discurso científico positivista. Realizada então a “purificação” da ciência jurídica, imunizado o Direito dos demais conhecimentos que lhe desinteressavam, restava ainda uma tarefa a ser cumprida: traçar uma epistemologia dogmática geral. Era preciso estabelecer uma epistemologia dogmática fundamental que orientasse as demais dogmáticas regionais (como o Direito Penal, Direito Civil e etc). “É uma atividade pretendidamente objetiva e rigorosa que, através de uma elaboração racional das normas vigentes, explicita sua coerência, busca organizar a estrutura lógica inerente ao direito positivo” (WARAT, 1995, p. 41). Kelsen, então, “estabeleceu uma proposta epistemológica para a Ciência do Direito. A epistemologia pode ser vista, desse modo, como o campo privilegiado da crítica do conhecimento científico” (WARAT; PÊPE, 1996, p. 54).

[...] Kelsen penetrou na dogmática jurídica para construir os princípios da dogmática geral do Direito, tentando, com isso, suprir uma imensa lacuna. Por essa razão, é possível dizer que a teoria pura do Direito é simultaneamente uma epistemologia e uma dogmática geral do Direito (teoria geral). Podemos dizer que a tarefa foi cumprida com êxito, visto que atualmente Kelsen constitui uma referência quase obrigatória para o desenvolvimento dos diferentes ramos da dogmática jurídica (WARAT; PÊPE, 1996, p. 55).

As condições fundantes desta epistemologia representa a imunização da ciência jurídica através da distinção do saber jurídico dos outros saberes. Isso, em que pese soe comum a teoria proposta por Kelsen, tem grande relevância para a epistemologia que estava sendo proposta naquele tempo. Quer dizer que nem mesmo a uma epistemologia dogmática do Direito interessa saber, ou debruçar-se, sobre os efeitos das normas no seu campo de atuação: “exclui-se a genealogia dos discursos jurídicos, ou seja, a análise histórica das condições políticas que tornaram possíveis esses discursos” (idem, ibidem, p. 57). O que interessava a esta epistemologia era uma dogmática geral pura do Direito. Não era tarefa da epistemologia refletir sob "problemas" ou "inconvenientes” que as normas poderiam produzir no campo social, trabalho que ficaria a cargo de outras áreas do saber, tais como uma Política do Direito ${ }^{7}$. “Apoiando-se no princípio da pureza

\footnotetext{
${ }^{7}$ [...] "é conveniente não esquecer que o postulado kelseniano da pureza metódica separa o conhecimento
} do Direito de sua função na sociedade”. (idem, ibidem, p. 57). 
metodológica, Kelsen pretende estabelecer a base para um conhecimento do Direito que neutralize possíveis componentes políticos. Considera conveniente, para a constituição de uma racionalidade jurídica específica, estabelecer uma distinção rigorosa entre o saber jurídico e a política” (idem, ibidem, p. 57).

\title{
3 CRÍTICA À RACIONALIDADE DA TEORIA NORMATIVISTA DO DIREITO
}

Dos traços gerais aqui esboçados é possível verificar que a teoria normativista do direito tem a pretensão de neutralidade nos seus enunciados. A estrutura da teoria normativista pretende imunizar da ciência jurídica tudo aquilo que fosse alheio ao seu objeto: a norma. Então, a racionalidade do discurso científico do Direito volta-se completamente a uma estrutura lógico-normativa. Isso constrange qualquer empreendimento crítico da epistemologia jurídica no que trata a incidência do discurso normativo no campo social. Nada mais coerente segundo a pretensão da epistemologia dogmática proposta por Kelsen. Contudo, vale dizer que este constrangimento reside na convicção de cientificismo da ciência jurídica. Segundo Albano Pêpe (2002, p. 73-74):

\begin{abstract}
A visão 'cientificista' do mundo elabora uma concepção de racionalidade que restringe a circulação do conhecimento ao âmbito de uma razão única, deixando de lado outras concepções de conhecimentos elaborados no mundo vivido. De um modo geral, instaura-se um 'olhar panoptico' e totalitário, que denega a reflexão, que exclui todos os saberes que não cumprem o 'ritual metedológico' prescrito no método demonstrativo afeito às ciências empíricas, esquecendo toda uma tradição gnoseológica. Um único método, empíricoanalítico, que se dissimula em muitas formas, todas desprovidas de quaisquer vínculos com as teorias do conhecimento e de toda tradição crítico-reflexiva em nome de uma teoria das ciências, de uma epistemologia geral.
\end{abstract}

No cientificismo reside uma crença. “O ‘cientificismo’ significa a fé da ciência em si mesma, ou dito de outra maneira, o convencimento de que já não se pode entender a ciência como ‘uma' forma de conhecimento possível, senão que devemos identificar o conhecimento com a ciência” (PÊPE apud HABERMAS, 2002, p. 74). Em decorrência disso se cria um corpo, uma "comunidade científica apartada dos saberes constitutivos da cotidianidade”, despreocupada, portanto, com qualquer problematização dos postulados jurídicos na sociedade. E em decorrência desta especificidade cientificista dos discursos, em que a racionalidade de seus postulados operava a níveis metodológicos, lógicos e formais (epistêmicos), isto resultou num auto-referenciamento da comunidade científica 
que se arrogou da possibilidade de conhecer, refletir e debater os campos específicos das ciências positivistas sob a égide da racionalidade instrumental típica da modernidade, justamente por serem os detentores “capazes” de abrigar e produzir tal discurso.

Diante desta ambiência cientificista, ela retira dos demais atores sociais a possibilidade de discutir e refletir criticamente os postulados epistêmicos da ciência jurídica. “Resta tão somente cumprir 'respeitosamente' e com 'obediência devida', as ‘verdades’ oriundas do mundo positivista-científico” (PÊPE, 2002, p. 74). E retira porque os demais discursos não detém a racionalidade necessária para serem reconhecidos como discursos válidos. Luis Alberto Warat (1995, p. 119-121) denuncia de forma brilhante esta questão:

Com efeito, para o positivismo, se as pautas não são coercitivamente garantidas, poderão ser livremente silenciadas e ignoradas, colocando a sociedade à beira da barbárie. Esta é uma tese bastante autoritária, que exclui a racionalidade jurídico-moral de nosso cotidiano, simplesmente porque não tem força para se impor.

E conforme Albano Pêpe (2002, p. 76):

\begin{abstract}
Impedidos de pensar cientificamente, visto não pertencerem “desde sempre” à comunidade científica, os indivíduos, reproduzem incessantemente o pacto de submissão determinado pelo contrato originário da modernidade. Sob esta dimensão a esfera normativa fica cada vez mais restrita aos dispositivos reconhecidos e consagrados pelas ciências jurídicas, que impossibilitam qualquer experiência comunicativa e a conseqüente compreensão de seus fundamentos e das condições de legitimidade de suas práticas intervencionistas.
\end{abstract}

É de se dizer, aqui, que por mais que se dispenda esforços para uma pureza dos postulados científicos na sua abstração, é inescapável a condição de que serão dados de sentido e valorações atribuídos por todo um contexto em que estão implicados tais conceitos. Significa dizer, em suma, que não há um meta-domínio isento de dados humanos nas proposições que o cientificismo pretendia fazer. Isto operando no interior de uma crítica ao cientificismo. Outra problematização é a que, independente dos postulados cientificistas de pureza, “a significação jurídica está ligada às próprias condições sociais, determinando-as e por elas sendo determinadas. Nesse sentido, ver as normas como o sentido objetivo das condutas, como Kelsen pretende, não deixa de ser uma forma inadequada de apresentação da função social do Direito” (WARAT; PÊPE, 
1996, p. 58). Isto passa a ser um óbice à racionalidade até então proposta, que operava a níveis de validade do discurso jurídico-científico. Consequentemente,

[...] o postulado da pureza metódica, tal como Kelsen o desenvolve, não tem sustentação na medida em que propõe uma ruptura, mesmo que retórica, entre a produção das significações jurídicas e seu conhecimento científico. Vale a pena enfatizar: o papel social do Direito é estabelecido a partir da análise do poder do seu discurso na sociedade, que, em seu deslocamento permanente, cumpre funções políticas e ideológicas, determinando as condições materiais da vida social (idem, ibidem, p. 58).

Pois bem, “o positivismo jurídico orienta-se claramente no sentido de caracterizar cientificamente o conceito de Direito. Assim, o Direito é apresentado como um sistema de normas que dão sentido jurídico às ações sociais” (idem, ibidem, p. 59). E é em função disso que se torna insuficiente a análise meramente de validade dos postulados jurídicos enquanto ciência para cumprir um critério de racionalidade do discurso ${ }^{8}$. Quer dizer, à aplicabilidade ou à incidência de determinada norma não é mais suficiente saber de sua validade, se indiferente aos efeitos sociais de seus postulados. A aplicabilidade precisa ser efetiva, justamente por estes postulados terem incidência no campo social contestador/aceitador de determinadas regras. Neste contexto onde as regras têm incidência efetiva, a "aceitabilidade" das normas determinantes de conduta passa a ter uma importância central no debate sobre o Direito e, notadamente, à epistemologia jurídica em seu empreendimento crítico. Conforme Leonel Severo Rocha (2008, p. 1041),

\begin{abstract}
Por tudo isto, a filosofia analítica normativista, baseada em critérios sintáticosemânticos, conforme tinham proposto Kelsen e Bobbio, foi forçada a alterarse devido as suas dificuldades em fazer frente ao surgimento de novas exigências teórico-sociais. Para tanto, a analítica, na atualidade, foi obrigada a voltar-se para a análise de critérios pragmáticos de racionalidade. Nesta linha de idéias, o critério de verdade do neo-positivismo ligado a comprovação lógica e ou/semântica, voltado a intersubjetividade universal de uma demonstração dedutiva ou a verificação empírica dos enunciados, entrou em crise.
\end{abstract}

\footnotetext{
${ }^{8}$ Neste sentido: "A teoria positivista centra-se no desenvolvimento de uma ciência formal fundada na redução dos comportamentos sociais, que são apreendidos tão somente nos limites já estabelecidos por uma estrutura normativa previamente estabelecida. Uma estratégia reducionista de tal porte torna evidente que a ciência jurídica assim pensada constitui-se numa atividade social que se utiliza de modelos idealizados de conhecimento para sancionar um núcleo inalterável de valores abstratos. Sua finalidade: tornar independentes da experiência cotidiana elementos fundantes como o sentido da sociedade, das suas leis e das suas atividades políticas. Dessa forma, enquanto instituição social, a ciência jurídica operacionaliza e articula os significados jurídicos idealizados abstratamente e portanto ideologicamente, remetendo-os ao imaginário geral da sociedade”. (WARAT; PÊPE, 1996, p. 60).
} 
Não bastava então se fazer uma análise das normas em sua estrutura de validade enquanto critério de racionalidade da ciência jurídico-positivista, porque “o sentido do Direito é complementado pelo contexto [...]. Pode-se dizer, então, que uma das repostas à crise do normativismo é uma teoria hermenêutica que coloca a importância de compreender o Direito além da norma. [...] é correto dizer que é preciso compreender o Direito dentro da sociedade, que a norma jurídica é um dever ser formal” (ROCHA, 2008, p. 1041). Diante disso, a racionalidade do discurso jurídico fez com que o Direito tivesse de se abrir. A matriz hermenêutica para o Direito representa uma abertura de seu sistema, até então completamente reduzido a seu amálgama dogmático-normativo da racionalidade científico-positivista, conforme os patamares propostos pela matriz analítico-normativista desenvolvida por Kelsen.

\section{MAX WEBER E O PROBLEMA DO VALOR DO ÂMBITO DA CIÊNCIA: A SUPERAÇÃO DA NOÇÃO CLÁSSICA DE CIÊNCIA COMO FORMAÇÃO}

É preciso reconhecer uma mudança na forma de conhecer das ciências como uma crítica ao positivismo. Como brevemente tratado na introdução deste trabalho, esta mudança ocorre na estrutura da ciência, ou seja, temos de reconhecer uma dinamização e uma temporalização na formação do processo científico. Aliás, o próprio conceito de formação na ciência resta superado, dando lugar a uma noção de função da ciência. Ora, isto porque, no conceito de formação, processo tipicamente cultural, o humano carregava, junto de si, uma imagem ou representação de mundo. É o processo formativo que produzia essa imagem (representação) de mundo. Tratava-se de um processo secular que estava para além da profissionalização técnica. Superado o conceito de formação, o projeto humanista desaparece, pois já não há um sistema de saber absoluto para o conhecimento (ideia de formação que existia no conhecimento). Vale lembrar aqui, como causa de inadmissão de concepções absolutas do saber que, no final do século XIX, filosofia, como ciência, terminou. Não nos é mais possível o saber absoluto. Ora, tal “apartamento” implicou numa postura positivista, que é a atitude de sustentar o conhecimento nas ciências positivas (e não na filosofia, exaurida de sua grande crise, mais comumente conhecida como "o fim da grande filosofia”). O dilema, ou as duas torturas, se estabeleceu no sentido de que, ou se confiava na filosofia (e no idealismo do 
conhecimento absoluto), ou se apoiava no conhecimento científico, através de seu método e de sua lógica, e eis aí a atitude positivista.

A mudança de tal postura não passou incólume, pois sofreu uma série de contestações sobre a estrutura e a função da ciência, inclusive sobre aspectos de formação na própria ciência. O conceito de formação (bildung) é oriundo do iluminismo e humanismo modernos. Com a mudança da estrutura da ciência, há uma mudança de sua função, momento em que deixa de ser entendida como um processo de formação, processo capaz de satisfazer e conduzir à formação. A ciência passa a exercer uma função mais limitada e específica. Tal reviravolta é tratada com larga clareza no texto "A ciência como vocação” (1968), de Max Weber, onde fica evidenciado o fim da ilusão de que a formação do humano e de sua humanidade, conduzido pela ciência, pudesse ser realizado. O conceito de formação evoca uma ideia de imagem (mítico-teológica), segundo a qual, o ser humano não é uma espécie natural dentre outras espécies naturais, porque o ser humano carrega em si uma imagem da transcendência, do absoluto. Isso significa que o processo formativo do ser humano é um processo de realização dessa imagem. Então, formação, não é apenas adquirir conhecimento científico e técnico em determinada área, a formação teórica. Formar-se significa que os seres humanos, os indivíduos, devem passar por um processo de “cultivo” de uma dimensão universal em todos os sentidos (cognitivo, afetivo, moral, político etc). A formação, deste modo, é o desenvolvimento daquilo que está em estado não lapidado (bruto) nos indivíduos seja alçado a uma dimensão universal de valores (ontológica, portanto), e que devem ser promovidos. Assim, o conceito de formação estava para além de um entendimento de mera instrução técnica. Com a superação de ideia de formação, já não é possível sustentar que o humano carrega em si, no processo formativo, uma pretensão de universalidade.

Com isso, a pergunta pelo sentido da vocação científica será determinante para traças os limites do próprio conhecimento científico: este passa a assumir uma postura de “especialização” dentro de uma noção de “lei do progresso”. Há uma linha temporal progressiva que um sistema de pensamento absoluto já não comporta. A ciência não visa um sistema (universal) de conhecimento totalitário, finalizado e fechado. O conhecimento está numa linha aberta, em que o próprio conceito de especialização já nos faz reconhecer que não há totalidade alcançável ou um limite para o “conhecer”. Pois bem, através da noção de progresso (brevidade) e de dinamização do conhecimento científico, importa em reconhecer que, em determinado momento, o conhecimento produzido cientificamente será superado em algum sentido. 
Evidenciado o abandono de qualquer empreendimento de conhecimento universal ou absoluto por mediação da ciência, Weber (1968, p. 31) nos remete a uma noção fundamental denominada como racionalização intelectualista: “não existe nenhum poder misterioso ou imprevisível que interfira no curso de nossas vidas”. Trata-se aqui de um processo de desencantamento de mundo, em que a ciência irá contribuir fundamentalmente, frustrando qualquer tentativa de contribuição humanista através da ciência. Então, o processo de racionalização intelectualista, em última instância, é um processo técnico, objetivo e tem essa significação teórica e técnica: o desencantamento do mundo. É uma prática que conduz a isso. Ora, se à dimensão de ciência escapa um projeto de formação, Weber nos leva a crer, com razão, que, para o cientista, não há sentido possível para a ciência, dentro da ideia de formação que restou superado. Então, o seu questionamento desloca-se do âmbito de interrogação do cientista e passa a ser um problema para os sujeitos e para a sociedade, de forma geral, justamente porque aí se coloca uma problemática do sentido da técnica-científica. A questão já não é mais sobre a vocação científica apenas, mas o que significa a ciência e qual o seu sentido no contexto da vida humana. Logo, a questão se desloca do eixo do cientista e se realoca no sentido da ciência para o humano, de forma geral. "O problema agora é saber o que significa ciência enquanto vocação no contexto da vida humana e qual o seu valor” (idem, ibidem, p. 33). Ou seja, qual o conceito de conhecimento para a ciência é uma pergunta que se impõe, já que não podemos conhecer a “verdadeira natureza” do humano através da ciência. E Weber, ironicamente, coloca um questionamento importante sobre tal reflexão:

\footnotetext{
Após a crítica devastadora que Nietzsche moveu aos "últimos homens" que "tinham encontrado a felicidade”, posso deixar de lado o ingénuo optimismo que enalteceu a ciência, isto é, a técnica cientificamente fundamentada da dominação da vida, como o caminho para a "felicidade". Quem é que ainda acredita nisso - afora algumas crianças grandes que habitam as cátedras ou as salas de redação dos jornais?
}

A conclusão de Weber é de que não há sentido na ciência. Não se pode justificar valores e sentidos através da ciência, em que pese ela os pressupor. Precisamente aqui se insere um problema fundamental, porque não há ciência sem pressupostos. E tais pressupostos é o que há de menos problemático, pois "a ciência pressupõe ainda que o resultado que o trabalho científico leva é importante em si, isto é, merece ser conhecido” (WEBER, 1968, p. 38). Ora, se o trabalho da ciência é importante, ele tem um valor. Ser importante é um qualificativo. E mais, se o trabalho científico merece ser conhecido está- 
se diante de um campo do dever-ser. Max Weber (idem, ibidem, p. 38) irá dizer, “a ciência tem um suposto normativo”, um suposto valorativo. Não há ciência sem valores. Em um nível mais geral, que não é um valor de conteúdo, toda a investigação científica supõe que os resultados em que se chega (provisórios, parciais, falíveis etc), eles são importantes, eles tem valor. Há um valor em conhecer um certo domínio”. E isso é um pressuposto valorativo. Segundo Weber (idem, ibidem, p. 39):

\begin{abstract}
Todo o trabalho científico tem sempre como pressuposto a validade das regras da lógica e da metodologia, que são os fundamentos gerais da nossa orientação no mundo. Ora, estes pressupostos não suscitam grandes problemas, pelo menos no tocante à nossa questão particular. Mas pressupõe-se ainda que o resultado do trabalho científico é "importante", no sentido de que é "digno de ser sabido". E aqui residem, evidentemente, todos os nossos problemas. Pois semelhante pressuposto não é, por seu lado, passível de uma demonstração científica. Só se pode interpretar de acordo com o seu sentido último, e deve rejeitar-se ou aceitar-se de harmonia com a atitude derradeira que cada um tem perante a vida.
\end{abstract}

E aí, a colocação imprescindível de Weber, e talvez a mais dramática, pois que este pressuposto escapa a qualquer demonstração por meio científico. Que a ciência tem valor, não é um pressuposto que pode ser cientificamente justificado, diferentemente da noção tradicional de ciência, na apreensão do conhecimento absoluto, ainda derivado da filosofia idealista de Hegel. Vale dizer que Weber trata de um tipo de racionalidade instrumental, típica das ciências descritivas. Ora, para tais saberes, das ciências da natureza, encontramos uma redução daquilo que é possível conhecer através desse tipo de ciência e de seus métodos. Então, está-se diante de um domínio técnico da vida, em que a ciência tem capacidade de gerar um conhecimento de tipo condicional ao seu método de proceder. Porém, algo lhe escapa: uma dimensão de valor que não pode ser cientificamente justificado. Ora, tal frustração do empreendimento científico descritivo, de uma razão prático-instrumental, provém notadamente no reconhecimento da existência de diversas ordens valorativas e impossibilidade de uma ordem valorativa universal. Nas palavras de Weber (1968, p. 41), “tal atitude é, em princípio, absurda, porque as diversas ordens de valores se defrontam no mundo, em luta incessante”. Então, a ciência terá algo a nos dizer somente quando aceitamos determinados pressupostos valorativos, inquestionável no interior da própria ciência. De uma forma mais capciosa, por assim dizer, quando Weber reconhece, na racionalização intelectualista, a produção do desencantamento de mundo, ele acaba por revelar justamente que não há ciência ou tecnologia sem pressuposições valorativas, que não há uma única ordem de valores e que 
tais ordens estão em conflito. O "desencantamento" mostra que, do ponto de vista valorativo, continuamos ainda vinculados a diferentes ordens valorativas. Então não há desencantamento completo, e este é um outro problema, incabível de ser discutido aqui. Contudo, o resultado do desencantamento de mundo consiste em mostrar que não há ciência das ordens valorativas. Mas, do ponto de vista do conhecimento instrumental, na relação de meios e fins, e se se aceitar determinados valores, a ciência pode sim oferecer os meios para preservar a vida, por exemplo.

Mais aí reside um problema muito sério, eis que, conforme Hans Albert, em seu tratado da razão crítica, "se o conhecimento científico é um campo da práxis social, no qual valorações e decisões desempenham um papel considerável, então é natural a pergunta se não surgem consequências para o princípio de ausência de valoração da ciência formulado por Max Weber” (ALBERT, 1976, p. 83). Percebe-se que o princípio de ausência de valoração, portanto, é um princípio metódico cujo qual cumpre uma função normativa no âmbito das ciências. Max Weber, desta forma, “caracterizou um princípio que se deixa manter sem grandes dificuldades, pelo menos para grande parte da ciência, de modo que seus adversário no debate de juízos de valor em geral, só reivindicam uma posição metodológica privilegiada para determinadas ciências” (ALBERT, 1976, p. 8384). Para este tipo determinado de ciência (não descritiva), o princípio de ausência de valoração formulado por Max Weber é inútil, e aí se aloca a necessidade de um reconhecimento de uma metodologia a que não se valem as ciências da natureza, em seu legado instrumental. Conforme Hans Albert: “Assim, ainda hoje, é muitas vezes feita uma reivindicação de autonomia metodológica para as chamadas ciências do espírito, que deve excluir a aceitação do postulado de Max Weber”.

O aparecimento de outro tipo de racionalidade prescritiva - ao nível de organização prática, ao nível da comunicação, ao nível ético - trata-se de uma questão grave, pois “a racionalidade ao nível dos enunciados prescritivos é algo que não se comprova facilmente dentro das tendências científicas atuais” (STEIN, 1987, p. 52-53). Contudo, o questionamento que se impõe agora, problema ainda insolúvel numa tradição de racionalidade descritiva (instrumental) que constrange praticamente toda pretensão de racionalidade em qualquer campo da ciência, como tal racionalidade, típica das ciências da natureza, poderá justificar valores com o intuito de lhes dar racionalidade. A resposta será negativa. Em primeiro lugar, temos de reconhecer a existência, na racionalidade descritiva, que, em que pese aparentemente suficiente para dar conta de sua estrutura interna dos discursos, no que trata a coerência de seus postulados o seu limite vai até a 
pressuposição de valores. Isso nos exige uma mudança de eixo metodológico. Em segundo lugar, temos de reconhecer que, paras as ciências histórico-hermenêuticas, como no caso do Direito, este tipo de racionalidade - descritiva - não deixa de ser uma forma inadequada para tratar de um expediente em que opera o Direito, notadamente no tecido social. Mas há razões para esta convicção.

\section{CONCLUSÃO}

No mundo jurídico, em particular, a discussão acerca do tema se faz ainda mais custosa, em decorrência da forma como a instituição Direito se coloca na sociedade e que, assim me parece, outros campos das ciências sociais não experimentam (ou, pelo menos, experienciam em um nível diferenciado). As principais razões para tal dificuldade, e para a diferenciação, igualmente, residem no fato de que i) a linguagem jurídica detém o monopólio da violência para a realização de seus postulados normativos, estando suscetível, portanto, a efeitos contestadores mais incisivos e violentos no campo da aplicabilidade de suas normas prescritivas de conduta; ii) em que pese o abandono das metafísicas no âmbito da produção do saber científico - e do mundo da vida também (concepção de ciência já apartada da filosofia pós-hegeliana), reside no discurso jurídico certa pretensão, ao meu ver, inescapável, de universalidade de seus postulados normativos, isso no interior e nos limites da soberania estatal (notadamente, no Estado moderno). Evidentemente que a soberania dos Estados sofre, atualmente, certo alargamento em sua postura política e entendimento, especificamente na contemporaneidade, por uma série de modificações que decorrem do próprio ambiente político internacional pós-guerra, e que hoje se movimentam mais densamente; iii) a linguagem jurídica é tipicamente deontológica, ou seja, imputa ao ser um dever (deverser), porém, contrário do que ocorre nas demais deontologias, a jurídica é coativa (obrigacional). Significa que não depende da voluntariedade do ser o cumprimento de certo dever: o dever lhe é imposto coativamente, através do monopólio da violência legal realizado na figura do Estado; iv) a linguagem jurídica é reducionista, ou seja, ela reduz a compreensão possível sobre o sujeito a um sentido normativo previamente prescrito (a exemplo do mundo dos fatos jurídicos). Contudo, e essa é uma ressalva válida, no discurso jurídico não é o ser que projeta seu fim (como ocorre nos discursos éticos e morais, de forma geral), mas seu sentido vem “desde fora”, ou seja, do interdito jurídico 
que lhe imputa determinada sanção, em caso de conduta diversa; e, por fim, v) as epistemologias, naturalmente, trazem, já junto de si, suas próprias margens. Numa relação de mutualidade, atua no seu limite para o conhecimento do seu objeto; por sua vez, seu objeto, lhe faz reconhecer seus limites. É o que podemos denominar como "estrutura de sentido”, ou, de logos apofântico: estrutura pré-disposta à realização da interpretação epistemológica ou científica sobre seu objeto. E por mais puída que seja a utilização do termo "objeto", nas ciências-humanas o objeto fala (e esse é um problema grave para a racionalidade).

Das razões acima apontadas, reconhece-se no discurso jurídico a discussão de valores e de preceitos éticos por excelência, em que pese esculpidos no ambiente normativo e de burocracia legal. E, por mais formalmente consistente o pensamento epistemológico intrínseco do Direito, devemos nos dar conta que, no campo de sua aplicabilidade, sua pretensão de validade irá depender da legitimidade de seus postulados que, ao contrário do que se pensa, não se encontra na legalidade. A legitimidade será uma pretensão que somente se realizará com o pouso da prescrição normativa no tecido social. Dos apontamentos acima delineados, remonta um panorama tal que a epistemologia jurídica deve ficar atenta, de forma crítica. E para isso, será necessário dois deslocamentos no âmago do discurso jurídico: o primeiro deslocamento será um apartar-se da tradição positivista descritiva para se pensar sua racionalidade, pelos motivos tratados no capítulo 3 deste texto, ou seja, os curtos limites em tratar de um tipo de racionalidade descritiva que é incapaz de justificar valores e preceitos éticos. Como se viu, no positivismo jurídico, conforme se estabeleceu epistemologicamente na modernidade, tratado no capítulo 2, se afigura inadequado no que trata sua pretensa autonomia de aplicabilidade das normas, justo por ser incapaz de justificar os valores contidos no conteúdo normativo; o segundo deslocamento exige do epistemólogo do Direito uma postura de desvencilhar a imagem arraigada e secular do Direito compreendido como ciência do Estado. É neste segundo deslocamento que devemos reconhecer um método próprio do Direito em tratar para com seu “objeto”: a norma. A pretensão de aplicabilidade normativa somente se concretizará no âmbito da legitimidade, ou seja, na acedência ou não acedência dos postulados valorativos incorporados na norma por parte de seus jurisdicionados.

Percebe-se aí um claro deslocamento metodológico, uma vez que, em que pese a consistência interna de seu discurso (formal), a separação de sua exigência externa (legitimidade) não passa de um artifício retórico, pois será somente na aplicabilidade da norma que se verificará a legitimidade dos postulados valorativos do discurso jurídico. É 
aqui que reside a justificativa para se pensar o Direito como uma ciência históricohermenêutica, abandonando de vez o constrangimento generalizado que as ciências naturais e sua inata racionalidade descritiva exerc sobre os demais campos do saber, pois será em decorrência do comportamento do “objeto” da ciência jurídica, ao longo da história, que irá definir uma metodologia mais adequada ao seu tratamento. E tal mudança de perspectiva do horizonte metodológico não ocorre apenas com o Direito, mas com as ciências do espírito, pelo que diz Hans-Georg Gadamer, numa conferência intitulada "Problemas epistemológicos das ciências humanas” (2003), com perfeição de argumento que comumente se espera do filosofo. E os debates remontam também aquilo que, na introdução deste texto denominou-se como "privilégio”. Em Gadamer (2003, p. 18), o privilégio remete à ideia de consciência histórica:

\footnotetext{
Entendemos por consciência histórica o privilégio do homem moderno de ter plena consciência da historicidade de todo presente e da relatividade de toda opinião. Os efeitos dessa tomada de consciência histórica manifestam-se, a todo instante, sobre a atividade intelectual de nossos contemporâneos [...].
}

Com o reconhecimento de uma consciência histórica, dirá Gadamer, “é preciso que cada qual esteja plenamente consciente do caráter particular de suas perspectivas” (2003, p. 19). Deve ser reconhecida, então, a existência de visões de mundo completamente distintas e valores igualmente distintos, havendo aí uma espécie de tensão entre visões de mundo (weltanschauung) e luta por visões de mundo (Kampf der weltanschauungen). Sem embargo não estarmos tratando da questão de conflito de culturas, o reconhecimento de visões de mundo distintas nos mostra a ausência de universalidade de nossas proposições e, além disso, e não menos importante, de como nos é possível constituir e produzir saberes, os mais diversos, fazendo-nos questionar, em última instância, qual a utilidade e para que se prestam tais saberes, provocação que motivou a conferência de Max Weber, brevemente comentada acima. Será preciso realizar uma interpretação, aqui, acerca da questão da metodologia adotada pelo discurso jurídico. Interpretar, pois se torna necessário uma reflexão explícita sobre as condições que levam o discurso jurídico (e o discurso das ciências, de forma geral) a ter esse ou aquele significado, algo que, por vezes, nos parece oculto ou de difícil acesso. Qual o sentido, então, do alcance de uma consciência histórica no plano do conhecimento científico é a pergunta que se coloca diante de nós neste momento. Gadamer coloca a questão da seguinte forma: 
“[...] Também as ciências humanas servem-se de um método de interpretação, o que as situa na esfera de nosso interesse. Perguntamos qual é o sentido e o alcance da consciência histórica no plano do conhecimento científico. Colocamos aqui o mesmo problema ao nos interrogarmos sobre a idéia de uma teoria das ciências humanas. Deve-se notar, entretanto, que a teoria das ciências humanas não se reduz à simples metodologia de um determinado grupo de ciências; como veremos a seguir, ela é propriamente filosófica e num sentido bem mais radical do que, por exemplo, a metodologia das ciências da natureza” (2003, p. 20).

Diante disso, é preciso reconhecer nas ciências humanas um problema tipicamente filosófico, segundo Gadamer. "Se as ciências humanas entram em uma relação determinada com a filosofia, isto não se dá somente numa perspectiva puramente epistemológica” (GADAMER, 2003, p. 20). E continua: “as ciências humanas não se limitam a pôr um problema para a filosofia. Ao contrário, elas põem um problema de filosofia” (GADAMER, 2003, p. 20). Neste sentido, é preciso reconhecer no “problema filosófico" que ora se levanta diante nas ciências humanas a sua autonomia em relação às demais ciências descritivas ou naturais. Nas palavras de Gadamer (idem, ibidem, p. 20):

[...] Mas se, ao contrário, percebermos as ciências humanas como um modo autônomo de saber, se reconhecermos a impossibilidade de submetê-los ao ideal de conhecimento próprio às ciências da natureza (o que implica considerar absurdo trata-las segundo o ideal de semelhança mais perfeita possível com os métodos e graus de certeza das ciências da natureza), então é a própria filosofia que está em questão, na totalidade de suas pretensões.

Aqui é preciso reconhecer que, na busca das ciências humanas por racionalidade há uma tendência mais ou menos geral de apoiarem-se nas ciências da natureza. Talvez isso ocorra em face de uma espécie de grande "ressaca metafísica” ocorrida após o despertar das ciências modernas e do desencantamento do mundo da vida. Parece temermos uma nova recaída ao domínio do sagrado numa tendência quase intuitiva em universalizar o mundo, de novamente buscar no olhar das coisas uma espécie de essência. É justamente isso que acaba de ser dito que Gadamer irá reconhecer na sua fala: “é verdade que as ciências humanas procuram permanentemente apoio na filosofia contemporânea, mas não é menos verdade que, para se assegurarem de uma boa consciência científica, tais ciências continuam atraídas pelo modelo das ciências da natureza quando elaboram seus métodos histórico-críticos” (idem, ibidem, p. 21). E a mera regularidade do procedimento "reaproveitado" das ciências da natureza não é outra coisa senão velar o problema que se oculta nas ciências humanas: “a simples constatação 
de que a descoberta de regularidade realiza um progresso efetivo nas ciências humanas não faz mais, em última instância, do que encobrir o verdadeiro problema posto por essas ciências” (idem, ibidem, p. 23). Em grande parte, o problema que se instaura nas epistemologias, notadamente nas que se debruçam sobre as ciências humanas, trata-se de reconhecer uma busca histórica, através de estruturas de compreensão, acerca do valor e do sentido que se põe diante de nós. Ora, evidentemente que uma racionalidade de tipo descritivo não dará conta de tal empreendimento, "pois o que quer que se entenda por ciência, não será encontrando regularidades, nem as aplicando aos dados históricos, que se apreenderá o elemento específico do conhecimento histórico” (GADAMER, 2003, p. 23). A despeito da questão da compreensão histórica necessária à uma racionalidade nas ciências humanas, assim se posiciona Gadamer:

\begin{abstract}
[...] a verdadeira intenção do conhecimento histórico não é explicar um fenômeno concreto como caso particular de uma regra geral, mesmo que esta última fosse subordinada aos desígnios puramente práticos de uma eventual previsão. Seu verdadeiro objetivo - mesmo utilizando-se de conhecimentos gerais - é antes compreender um fenômeno histórico em sua singularidade, em sua unicidade. O que interessa ao conhecimento histórico não é saber como os homens, os povos, os Estados se desenvolvem em geral mas, ao contrário, como este homem, este povo, este Estado veio a ser o que é; como todas essas coisas puderam acontecer e encontrar-se aí (2003, p. 23-24).
\end{abstract}

Com o termo compreensão, Gadamer nos remete imediatamente a uma abordagem hermenêutica, ou melhor, é tarefa própria da hermenêutica compreender historicamente. Segundo Gadamer (2003, p. 57), “o conhecimento histórico não pode ser descrito segundo o modelo de um conhecimento objetivista, já que ele mesmo é um processo que possui todas as características de um acontecimento histórico”. A marca que se imprimi aqui, neste tipo de racionalidade comunicativa, é o horizonte de compreensão que se abre diante de nós com a hermenêutica, nos desiludindo, por sua vez, do objetivismo dos enunciados descritivos típicos da racionalidade instrumental das ciências naturais. Em vias de conclusão, precisamos reconhecer aqui o trabalho desenvolvido por Habermas, capaz de dar densidade ímpar ao discurso jurídico. Podemos encontrar em Habermas, em sua teoria do agir comunicativo, uma superação à instrumentalidade da racionalidade, de forma que, se remete há uma dimensão da compreensão (intersubjetiva) no âmbito de pretensão de legitimidade da aplicação da norma, através do entendimento, através de um agir comunicativo. "E o agir comunicativo vem a ser a disponibilidade que existe entre falantes e ouvintes a estabelecer um entendimento que surge de um consenso sobre algo no mundo" (MOREIRA, 2004, p. 110). 
Logo, será na pretensão de aplicabilidade das normas, no seu pouso sobre o tecido social, que este tipo de racionalidade comunicativa exigirá do discurso jurídico um método não objetivista ou reducionista quando de seu empreendimento epistemológico. A insuficiência da racionalidade instrumental decorre da ideia de que o Direito exerceria autonomia à moral: "através da utilização dessa racionalidade autônoma que vai ser possível a Weber articular uma concepção de legalidade que se legitima a partir de si mesma” (MOREIRA, 2004, p. 65). Trata-se, portanto, de um discurso que se entende racional à medida que essa racionalidade emana de qualidades formais próprias. “A presença de elementos morais e de uma justiça material no âmbito jurídico acarreta, segundo a interpretação dada por Habermas ao pensamento de Weber, a destruição da racionalidade formal inerente ao Direito” (idem, ibidem, p. 66). Estar-se-á diante de discussões acerca de valores e preceitos éticos, insolúveis aos olhos do princípio da ausência de valor formulado por Weber, no uso metodológico de uma racionalidade instrumental. No campo do Direito, por excelência, a mudança de perspectiva metodológica além de necessária, é condição de racionalidade para seu discurso. Ora, a separação da legitimidade da ideia de legalidade (noção de autonomia em relação às regras morais, segundo Weber), é condição para a realização do Estado democrático de Direito, em detrimento do Estado de Direito. A legitimidade exige da epistemologia uma postula hermenêutica no que trata seu método, pois evoca para si o reconhecimento de uma estrutura histórica de compreensão e intersubjetiva (comunicacional). Nestes limites é possível reconhecer o que há de democracia no pensamento epistemológico do Direito.

\footnotetext{
Abstract: At first, the article will address the legal discourse as a science of state, from modernity, because this time is fundamentally marks the state as centralized entity and manufacturer standards. In a second phase will analyze the rhetorical cut at the heart of the legal scientific principles, notably the normative theory of law developed by Hans Kelsen, in which the legal discourse would allegedly alienated from social and political issues. Subsequently, we start from the hypothesis of the law as a cultural institution and the problem of landing the normative sense in the social fabric. Finally, we will analyze the possibility of a prescriptive stance of Law, where he will emphasize the need to substantiate and give consistency to values inside their own legal discourse, since there is a privileged place to base values except through a theory of argument, considering the subject of standards in the context that emerges in the social and political conditions that are inherent. Thus, the present work is to thread this theme, which requires the legal discourse in contemporary times, a change in methodological perspective as a condition for the realization and understanding of the fundamental rights.
} 
Keywords: Legal Discourse. Instrumental Rationality. Epistemology. Fundamental Rights. Hermeneutics.

\section{REFERÊNCIAS}

ADEODATO, João Maurício. Pressupostos e diferenças de um direito dogmaticamente organizado. Boletim da Faculdade de Direito, Coimbra, 1999/2000.

ALBERT, Hans. Tratado da razão crítica. Tradução de Idalina Azevedo da Silva, Erika Gudde e Maria José P. Monteiro. Rio de Janeiro: Editora Tempo Brasileiro, 1976.

GADAMER, Hans-Georg. O problema da consciência histórica. Tradução de Paulo César Duque Estrada. 2ª Ed. Rio de Janeiro: Editora FGV, 2003.

HABERMAS, Jürgen. Teoria do agir comunicativo: racionalidade da ação e racionalização social. Tradução de Paulo Astor Soethe. São Paulo: Editora WMF Martins Fontes, 2012

JAPIASSU, Hilton. Introdução ao pensamento epistemológico. $2^{\text {a }}$ Ed. Rio de Janeiro: Editora Livraria Francisco Alves, 1977.

KELSEN, Hans. Teoria Pura do Direito. 6a Ed. São Paulo: Editora Martins Fontes, 1998.

MOREIRA, Luiz. Fundamentação do Direito em Habermas. $3^{\text {a }}$ Ed. Belo Horizonte: Editora Mandamentos, 2004.

PÊPE, Albano Marcos Bastos. A Filosofia do direito e a filosofia prática: o 'ethos' enquanto mundo compartilhado: a questão da legitimidade no direito. 2002. $121 \mathrm{f}$. Tese (Doutorado em Direito) - Universidade Federal do Paraná, Curitiba, 2002.

ROCHA, Leonel Severo; KING, Michael; SCHWARTZ, Germano. A verdade sobre a autopoiese no direito. Porto Alegre: Livraria do Advogado Editora, 2009.

ROCHA, Leonel Severo. Da epistemologia jurídica normativista ao construtivismo sistêmico. Boletim da Faculdade de Direito, Coimbra, v. 1, p. 1033-1065. 

2003.

Epistemologia jurídica e democracia. $2^{\text {a }}$ Ed. São Leopoldo: Editora Unissinos,

STEIN, Ernildo. Paradoxos da racionalidade. Porto Alegre: Editora PyR, 1987.

WARAT, Luis Alberto. Introdução geral ao direito: a epistemologia jurídica na modernidade. Porto Alegre: Sergio Antonio Fabres, 1995.

WARAT, Luis Alberto; PÊPE, Albano Marcos Bastos. Filosofia do direito: uma introdução crítica. São Paulo: Editora Moderna, 1996.

WEBER, Max. Ciência e política: duas vocações. Tradução de Leonidas Hegenberg e Octany Silveira da Mota. São Paulo: Editora Cultrix, 1989. 